\title{
Direct Blue 2 Tekstil Boyar Maddesinin Agaricus campestris Biyokütlesi Tarafından Biyosorpsiyonu: Kinetik, İzotermal ve Termodinamik Çalışmalar
}

\author{
Aslı GÖÇENOĞLU SARIKAYA ${ }^{1 *}$, Emre ERDEN²@
}

${ }^{1}$ Bursa Uludağ Üniversitesi, Fen-Edebiyat Fakültesi, Kimya Bölümü, Bursa

${ }^{2}$ Ege Üniversitesi, Fen Fakültesi, Biyokimya Bölümü, İzmir

Geliş / Received: 02/07/2019, Kabul / Accepted: 20/02/2020

\section{$\ddot{O} \mathbf{z}$}

Bu çalışmada, Direct Blue 2 (DB2) tekstil boyar maddesinin Agaricus campestris'ten elde edilen biyosorbent ile sulu çözeltilerden giderimi çalışılmıştır. Biyosorpsiyona $\mathrm{pH}$, sıcaklık, başlangıç DB2 derişimi ve biyosorbent miktarı gibi parametrelerin etkisi incelenmiştir. Optimum pH'ın 6.0 olarak tespit edildiği koşullarda $100 \mathrm{mg} \mathrm{L}^{-1}$ başlangıç DB2 derişimi ve $0.01 \mathrm{~g}$ biyosorbentin kullanıldığı koşullarda maksimum biyosorpsiyon kapasitesi $38.56 \mathrm{mg} \mathrm{g}^{-1}, 0.2 \mathrm{~g}$ biyosorbentin kullanıldığı koşullarda ise \% tutunma miktarının \% 93.39 olarak bulunmuştur. Elde edilen sonuçlara göre biyosorpsiyonun Freundlich izoterm modeline ve yalanc1-ikinci derece kinetik modele uygun olduğu rapor edilmiştir. Son olarak, biyosorpsiyon mekanizması için termodinamik parametreler (standart serbest enerji, standart entalpi ve standart entropi) belirlenmiştir.

Anahtar Kelimeler: Agaricus campestris, Direct Blue 2, biyosorpsiyon, biyosorbent

\section{Direct Blue 2 Textile Dye Biosorption by Agaricus campestris Biomass: Kinetic, Isotherm and} Thermodynamic Studies

\begin{abstract}
In this work, the biosorption of Direct Blue 2 (DB2) textile dye from aqueus solution were studied by biosorbent which were obtained from Agaricus campestris. The effect of $\mathrm{pH}$, temperature, initial DB2 concentration and amount of biosorbent were investigated. When $100 \mathrm{mg} \mathrm{L}^{-1}$ initial concentration of DB2 and $0.01 \mathrm{~g}$ of biosorbent were used, the maximum biosorption capacity was determined as $38.56 \mathrm{mg} \mathrm{g}^{-1}$ under the optimum $\mathrm{pH}$, which was determined as 6.0 and $0.2 \mathrm{~g}$ of biosorbent were used, the $\%$ removal was determined as $93.39 \%$. It was reported as, biosorption process was fitted Freundlich isotherm model and pseudo-second order kinetic model. In addition, the thermodynamic parameters (such as standard free energy, standard enthalpy, and standard entropy) were determined.
\end{abstract}

Keywords: Agaricus campestris, Direct Blue 2, biosorption, biosorbent

\section{Giriş}

Sentetik boyalar tekstil, deri, kozmetik, kağıt gibi birçok farklı endüstri alanında boyar madde olarak kullanılmakta ve atık olarak çevreye karışmaktadır (Prola vd., 2013). Göl ve akarsular gibi doğal su kaynaklarının bu tür boyar maddeler tarafından kirletilmesi sonucunda doğal ekosistem ve flora olumsuz yönde etkilenmektedir (Cardoso vd., 2012). Toksik ve kanserojen etkilerinin olması sebebiyle boyar maddelerin doğada bulunması özellikle canlı organizmalar için oldukça tehlikelidir. $\mathrm{Bu}$ nedenle boyar maddelerin atık sulardan uzaklaştırılması oldukça önemlidir (Sellaoui vd., 2017). 
Membran filtrasyonu, çöktürme, sinıflandırmanın haricinde, sulu koagülasyon, kimyasal ve biyolojik çözeltilerdeki partikül yüküne ve yöntemler atık sulardan boyar maddelerin çözünürlüklerine göre katyonik, anyonik ve giderimine yönelik kullanılan geleneksel non-iyonik boyar maddeler şeklinde de yöntemlerdir (Güzel vd., 2014). Fakat bu tür sinıflandırılmaktadırlar (Seow ve Lim, 2016). geleneksel yöntemlerin pahalı, zaman alıcı ve yan ürün olarak toksik maddelerin ortaya çıkması gibi dezavantajları mevcuttur. Kolay uygulanması, yüksek verim elde edilmesi, maliyetinin düşük ve tasarımının basit olması gibi birçok avantajından dolayı adsorpsiyon yöntemi son yıllarda atık sulardan boyar maddelerin gideriminde oldukça yaygın kullanılan bir yöntemdir (Sewu vd., 2017).

Biyosorpsiyon yöntemi, atı sulardan kirleticilerin gideriminde fizikokimyasal yöntemlere alternatif olarak kullanılan bir yöntemdir. $\mathrm{Bu}$ yöntemde yaprak (Jain ve Gogate, 2019), talaş (Rangabhashiyam vd., 2018), liken (Bayazit vd., 2018), mantar (Almeida ve Corso, 2019), alg (Chu ve Phang, 2019), maya (dos Santos vd., 2019) ve bakteri (Li vd., 2019) gibi farkl biyosorbentler kullanılmaktadır. Canlı ve cansız mikroorganizmaların kullanıldığı aktif ve pasif biyosorpsiyon olmak üzere iki farklı biyosorpsiyon çeşidi bulunmaktadır. Canlı hücrelerin kullanıldığg yöntemde hücrelerin çabuk kontamine olması, besiyerine ihtiyaç duymaları ve tekrar kullanımına olanak vermemesi gibi dezavantajları nedeniyle genellikle biyosorbent olarak ölü hücreler kullanılmaktadır (Fernandez vd., 2010).

Tekstil boyar maddeler boya molekülünün yapısına göre sınıflandırılabileceği gibi, rengine, yapısına ve uygulama yöntemine göre de sinıflandırılabilir. Asidik, bazik, reaktif, direct, mordant, dispers, azo ve kükürtlü boyalar tekstil endüstrisinde kullanılan boyar madde türleridir. $\mathrm{Bu}$ Kimyasal yapısında bir ya da birden fazla aromatik halka ve azo grubu (R-N=N-R') bağlı boya ajanı bulunan azo boyalar, tekstil endüstrisinde yaygın olarak kullanılmaktadır (Göçenoğlu Sarıkaya, 2019a).

Agaricus campestris, Agaricus bisporus'tan sonra en yaygın üretilen yenilebilir mantar türüdür. Biyokütlesinin kolay elde edilebilir ve yetiştirilmesinin kolay olması nedeniyle kirleticilerin biyosorpsiyonunda biyosorbent olarak kullanım alanı bulmaktadır (Göçenoğlu Sarıkaya, 2019b). Bu çalışmada, tekstil endüstrisinde yaygın olarak kullanılan Direct Blue 2 (DB2) diazo-boyar maddesinin sulu çözeltilerden biyosorpsiyonu çalışılmıştır. Biyosorbent olarak $A$. campestris'ten elde edilen biyokütle kullanılmıştır. Uygun koşulların belirlenebilmesi için $\mathrm{pH}$, boyar madde derişimi, sıcaklık, süre, biyosorbent miktarı ve rejenerasyonu gibi biyosorpsiyona etki eden parametreler belirlenmiştir. Bunun yanı sira biyosorpsiyonun mekanizmasının aydınlatılabilmesi için izoterm modelleri, kinetik ve termodinamik parametreler de ayrıca incelenmiştir. 


\section{Materyal ve Metot}

\section{Kullanılan kimyasallar}

Direct Blue $2\left(\mathrm{C}_{32} \mathrm{H}_{20} \mathrm{~N}_{6} \mathrm{NA}_{4} \mathrm{O}_{14} \mathrm{~S}_{4} ;\right.$ DB2) Aldrich (Steinheim, Almanya) firmasindan temin edilmiştir. Di-azo grubu olan boyanın kimyasal yapısı Şekil 1'de verilmiştir.
Potasyum dikromat (BioXtra, $\geq \%$ 99.5), tampon çözelti olarak kullanılan asetik asit (\% 99.8), sodyum asetat ( $\geq \% 99$ ), potasyum dihidrojen fosfat (\% 99.99) ve dipotasyum hidrojen fosfat ( $\geq \%$ 98) Sigma-Aldrich'ten temin edilmiştir. Kullanılan diğer tüm kimyasallar analitik derecelidir.

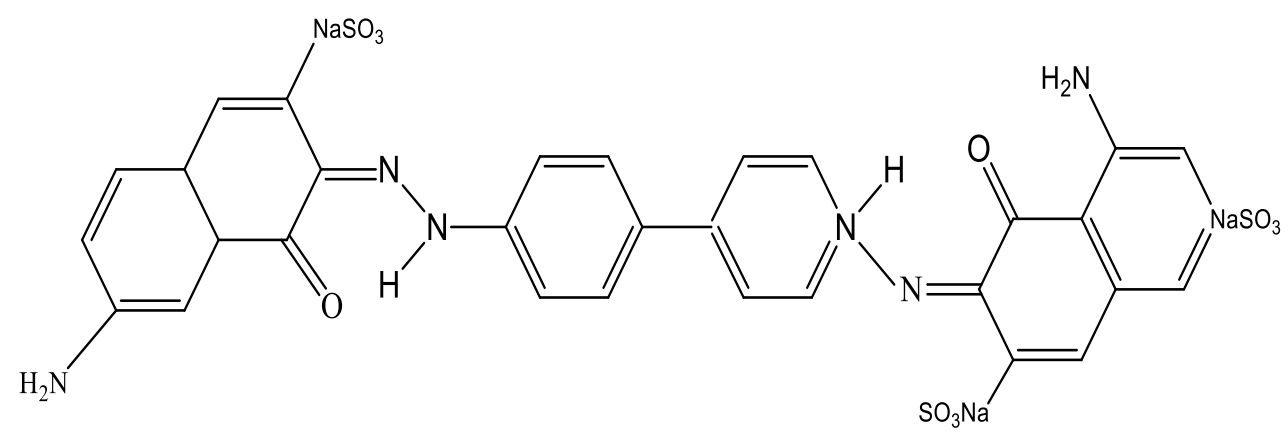

Şekil 1. Direct Blue 2 (DB2)'nin kimyasal formülü

\section{Biyosorbentin karakterizasyonu}

Biyosorbent olarak kullanılan A. campestris Müpa Mantarcılık A.Ş.'den temin edilmiştir. Biyosorbentin hazırlanması aşamasında $A$. campestris ilk önce destile su ile 3 kere yıkanmış, daha sonra $323 \mathrm{~K}$ sıcaklıkta etüvde kurutulmuştur. Daha sonra kurutulan biyokütle homojenizatörle 70-100 $\mu \mathrm{m}$ aralığında küçük parçalara ayrılmış, biyosorpisyon çalışmalarında kullanılmak üzere cam kavanozlarda muhafaza edilmiştir.

Biyosorbentin fonksiyonel gruplarının belirlenebilmesi ve kimyasal yapısının aydınlatılabilmesi için biyosorpsiyon öncesi ve sonrasında Fourier dönüşümlü kızılötesi (FT-IR) spektrofotometresi (Perkin Elmer Spectrum BX FTIR System) kullanılarak FTIR analizi gerçekleştirilmiştir. Biyosorbentin morfolojik özelliğinin belirlenebilmesi için biyosorpsiyon öncesi ve sonrasında taramalı elektron mikroskopu (SEM) ile SEM görüntüleri alınmıştır (ZEISS EVO 40).

\section{e Biyosorpsiyon çalışmaları}

Biyosorpsiyon çalışmaları $50 \quad \mathrm{~mL}$ 'lik erlenlerde $25 \mathrm{~mL}$ çalışma hacmi olacak şekilde tasarlanmıştır. Kesikli çalışma sisteminde ilk önce en uygun $\mathrm{pH}$ değeri tespit edilmiştir. Bunun için farklı $\mathrm{pH}$ değerlerinde (pH 3-5 asetat tamponu, 0.1 M; pH 5-8 fosfat tamponu, $0.1 \mathrm{M})$ boya çözeltileri $\left(50 \mathrm{mg} \mathrm{L}^{-1}\right.$ derişim) hazırlanarak ortama $0.025 \mathrm{~g}$ biyosorbent konulmuş ve $125 \mathrm{rpm}$ çalkalama hızında 293 K'de 3 saat inkübatörde karıştırılmıştır. Daha sonra uygun boya başlangıç derişimi (5-100 $\left.\mathrm{mg} \mathrm{L}^{-1}\right)$ ve sıcaklık değerlerinin $(277 \mathrm{~K}, 298 \mathrm{~K}$ ve $318 \mathrm{~K})$ belirlenebilmesi için uygun $\mathrm{pH}$ değerinde biyosorpsiyon çalışmaları gerçekleştirilmiştir.

Biyosorpsiyon sonras1 biyosorbentin biyosorpsiyon kapasitesi $\left(q_{e}\right)$ (Eşitlik 1) ve ortamda bulunan boya miktarının \% tutunma değeri (\%R) (Eşitlik 2) hesaplanmıştır:

$q_{e}=\frac{\left(C_{0}-C_{e}\right) V}{m}$ 
$\% R=\frac{\left(C_{0}-C_{e}\right)}{C_{0}} \times 100$

Denklemde $C_{0}$ değeri başlangıç DB2 derişimini $\left(\mathrm{mg} \mathrm{L}^{-1}\right), \quad C_{e}$ değeri denge halindeki DB2 derişimini $\left(\mathrm{mg} \mathrm{L}^{-1}\right), \quad V$ çözeltinin toplam hacmini $(\mathrm{mL}), m$ ise kullanılan biyokütle miktarını (g) vermektedir. Toplanan örnekler $10 \quad 000$ rpm'de santrifüjlendikten sonra renk ölçümü Ultraviyole-görünür 1şı $\quad$ (UV-Vis) spektrofotometresi (Perkin Elmer Lambda 35 UV/Vis Spektrometre) ile gerçekleştirilmiştir $\left(\lambda_{\max } 568 \mathrm{~nm}\right)$.

\section{Desorpsiyon ve tekrar kullanım}

Biyosorbentin biyosorpsiyon sonras1 tekrar kullanımının araştırılması için desorpsiyon çalışmaları gerçekleştirilmiştir. Desorpsiyon ve tekrar kullanım çalışmaları için $50 \mathrm{~mL}$ 'lik erlende toplam boya hacmi $25 \mathrm{~mL}$, biyosorbent miktarı $0.025 \mathrm{~g}$ olacak şekilde deney tasarlanmıştır. Desorpsiyon ajanı olarak $0.1 \mathrm{~N} \mathrm{HCl}$ ve $0.1 \mathrm{~N} \mathrm{NaOH}$ çözeltileri kullanılmıştır. Biyosorbent boya çözeltisi ile muamele edildikten sonra desorpsiyon ajanı ile tekrar çalkalamalı inkübatörde karıştırılmıştır. Bu işlemler $298 \mathrm{~K}$ 'de 3 saat gerçekleştirilmiş ve $5 \mathrm{kez}$ tekrarlanmıştır.

\section{Bulgular}

\section{Biyosorbentin karakterizasyonu}

Biyosorbent olarak kullanılan $A$. campestris' in DB2 ile biyosorpsiyonu öncesi ve sonrasında FTIR spektrumu alınarak, boyanın biyosorbe olmasında etkili olan fonksiyonel gruplarin belirlenmesi hedeflenmiştir. Şekil 2'de biyosorbente ait FTIR spektrumları verilmiştir. Elde edilen bulgulara göre, $3270-3280 \mathrm{~cm}^{-1}$ aralığında ve $1546 \mathrm{~cm}^{-1}$ 'de amino gruplarına ait gerilme titreşimleri gözlenirken, $1625 \mathrm{~cm}^{-1}$, serbest karboksil gruplarına ait absorpsiyon piki gözlenmektedir. 2940-2920 $\mathrm{cm}^{-1}$ bant aralığında ise $\mathrm{C}$-H gerilmesi gözlenmektedir. $\mathrm{C}-\mathrm{O}$ ve $\mathrm{N}-\mathrm{H}$ absorpsiyon pikleri ise sirasiyla 1019 ve $1028 \mathrm{~cm}^{-1}$ 'de gözlenmektedir (Bayramoğlu ve Arıca, 2007). Şekil 2 (b)'de görüldüğü gibi, DB2'nin biyosorbentle etkileşimi sonucu $3280 \mathrm{~cm}^{-1}$, de görülen keskin pik daha yayvan hale gelmiştir. Bunun yanı sıra, 1019 ve $1028 \mathrm{~cm}^{-1}$, de C-O ve NH'absorpsiyonuna ait piklerde $1010 \mathrm{~cm}^{-1}$, doğru bir kayma gözlenmektedir. Buna göre A. campestris'in DB2'yi biyosorbe ettiği anlaşılmaktadır. 


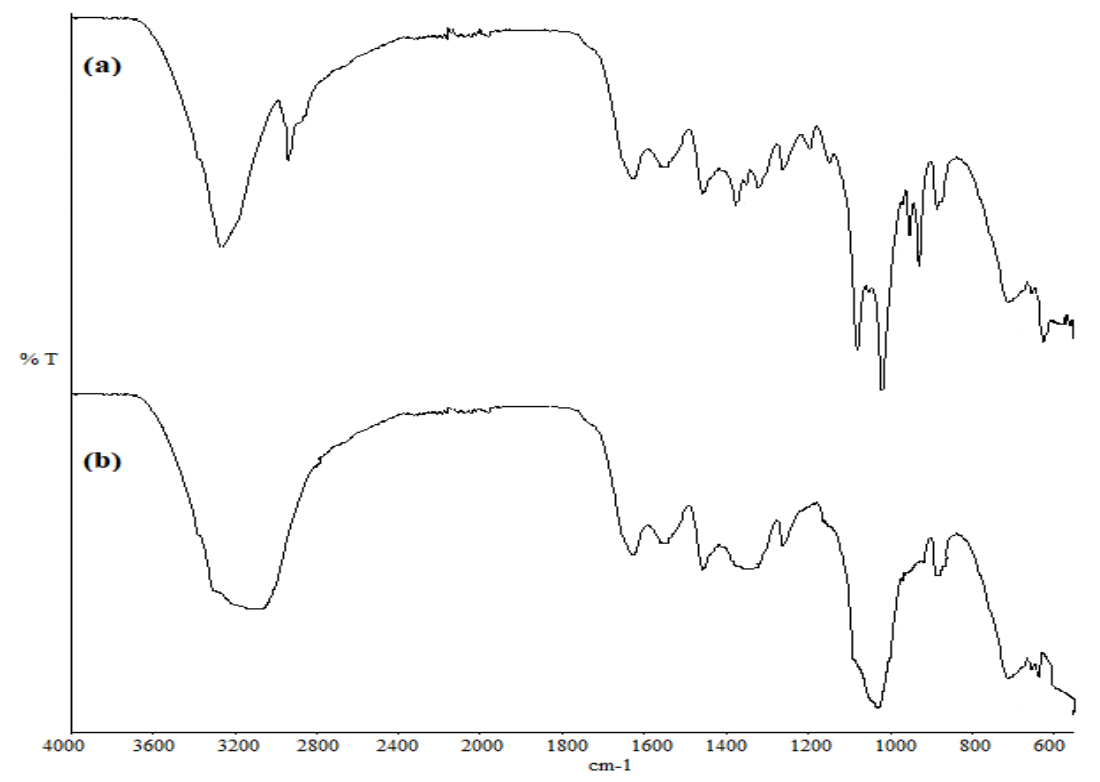

Şekil 2. A. campestris'e ait (a) biyosorpsiyon öncesi ve (b) biyosorpsiyon sonrası FTIR spektrumları

Biyosorbentin morfolojik özelliklerinin olduğu görülmektedir. Biyosorpsiyon sonras1 belirlenmesi için biyosorpsiyon öncesinde ve DB2'nin bağlanmasıyla yüzeyde değişim sonrasında SEM görüntüleri alınmıştır (Şekil olduğu ve daha pürüzsüz bir hale geldiği 3). Buna göre, biyosorbente ait yüzeyin görülmektedir. oldukça gözenekli ve bağlanmaya müsait

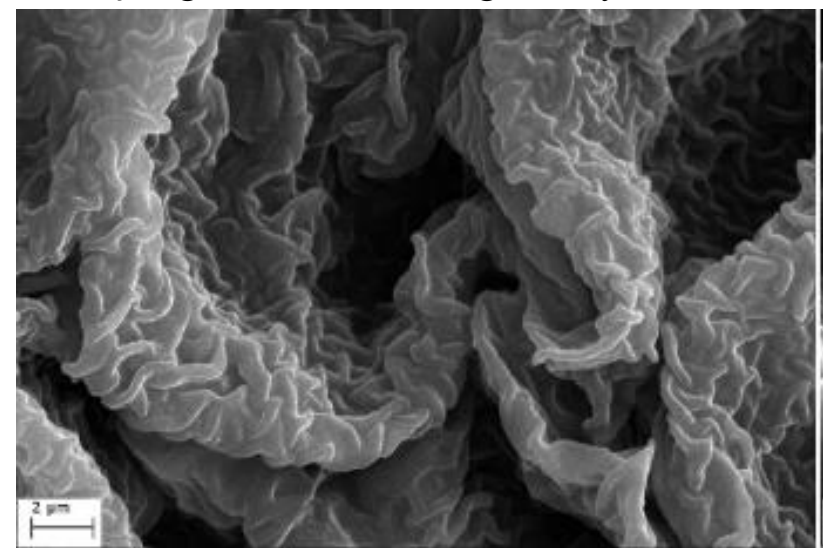

(a)

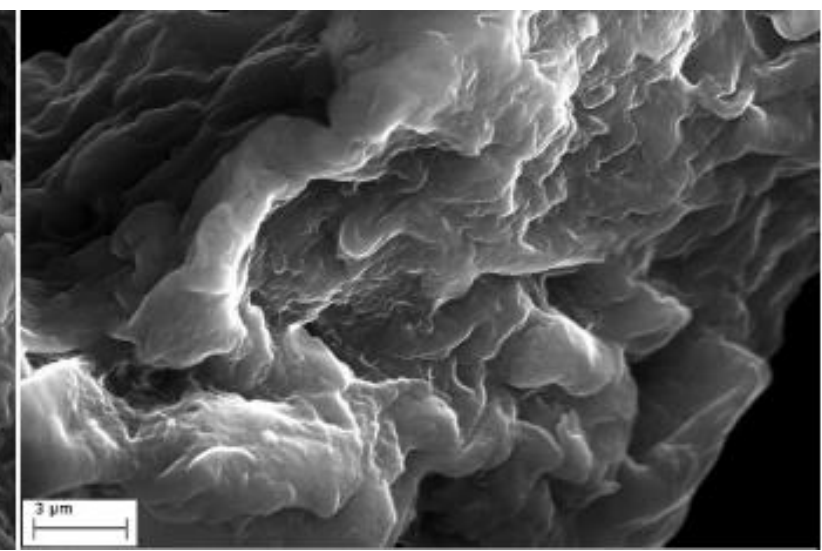

(b)

Şekil 3. A. campestris'e ait (a) biyosorpsiyon öncesi ve (b) biyosorpsiyon sonrası SEM görüntüleri

\section{Biyosorpsiyona pH etkisi}

Boyar maddelerin sulu ortamdan biyosorpsiyonunda $\mathrm{pH}$ değeri oldukça önemlidir. Ortamın pH değeri mikrobiyal hücre duvarında bulunan iyonlaşabilir grupların yükünü ve derecesini etkileyerek bağlanmanın gerçekleşmesinde önemli bir rol oynar (Mondal vd., 2017). Bu çalışmada, toplam hacim $25 \mathrm{~mL}$ olacak şekilde farklı $\mathrm{pH}$ değerlerinde DB2 çözeltisi hazırlanmış, 0.025 g biyosorbent konularak $298 \mathrm{~K}$ 'de 3 saat çalkalamalı inkübatörde (125 rpm) karıştırılmıştır. Elde edilen sonuçlara göre, 
biyosorpsiyon kapasitesinin $\left(q_{e}\right)$ ve $\left.\% \quad \mathrm{~g}^{-1}\right)$ ve $\% R$ değerleri (\% 68.70) en yüksek tutunma değerinin $(\% R)$ en yüksek olduğu $\mathrm{pH} \quad 6$ 'da gerçekleşmiştir. Elde edilen pH değeri 6 olarak bulunmuştur (Şekil 4). sonuçlara göre daha sonraki biyosorpsiyon Anyonik özellikte bir boyar madde olan çalışmaları pH 6'da hazırlanan DB2 DB2'nin farklı $\mathrm{pH}$ değerlerinde elektrostatik çözeltisinin kullanılmasıyla özelliği de değişmektedir. Şekil 4'te verilen gerçekleştirilmiştir.

grafiğe göre, A. campestris tarafindan

DB2'nin biyosorpsiyonuna ait $q_{e}(37.44 \mathrm{mg}$

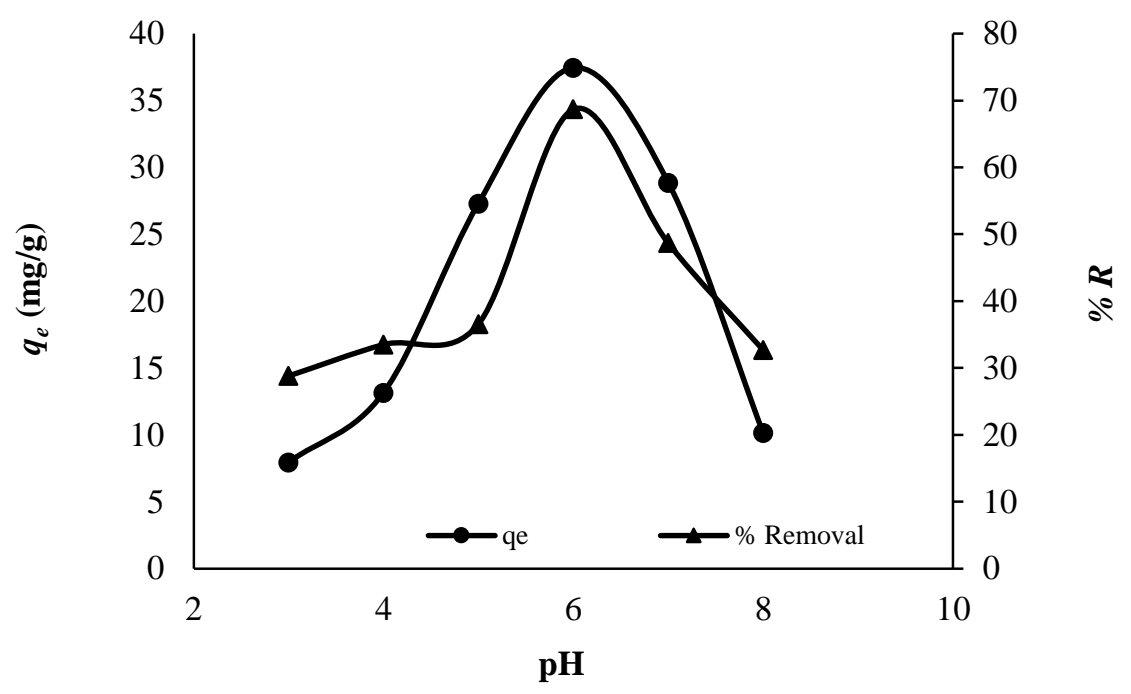

Şekil 4. DB2'nin A. campestris tarafından biyosorpsiyonuna pH etkisi 
Biyosorpsiyona başlangıç boyar madde derişiminin etkisi

Başlangıç boyar madde derişiminin etkisinin incelenebilmesi için 5-100 $\mathrm{mg} \mathrm{L}^{-1}$ derişim aralığında toplam hacim $25 \mathrm{~mL}$ olacak şekilde DB2'nin sulu çözeltileri hazırlanmış ve 298 K'de biyosorpsiyon gerçekleştirilmiştir. Biyosorbent miktarı $0.025 \mathrm{~g}$, biyosorpsiyon süresi 3 saat ve karıştırma hızı 125 rpm olarak ayarlanmıştır. Elde edilen sonuçlara göre, başlangıç DB2 derişiminin artmasıyla $q_{e}$ değeri de artmaktadır. $5 \mathrm{mg} \mathrm{L}^{-1} \mathrm{DB} 2$ derişiminde $q_{e}$ değeri $11.48 \mathrm{mg} \mathrm{g}^{-1}$ iken $100 \mathrm{mg} \mathrm{L}^{-1} \mathrm{DB} 2$ derişiminde bu değer $74.37 \mathrm{mg} \mathrm{g}^{-1}$, e çıkmaktadır. Başlangıç boyar madde derişiminin artmasıyla biyosorbent ve boyar madde etkileşimi de artış göstermektedir. Fakat artan boyar madde derişimiyle birlikte $\% R$ değerinde bir düşüş gözlenmiştir (\% 89.34'ten \% 34.16). Biyosorbentin biyosorpsiyon kapasitesinin artmasıyla yüksek derişimlerde biyosorpsiyon gerçekleşemez ve boyar maddenin $\% R$ değerinde bir düşüş gözlenir (Şekil 5).

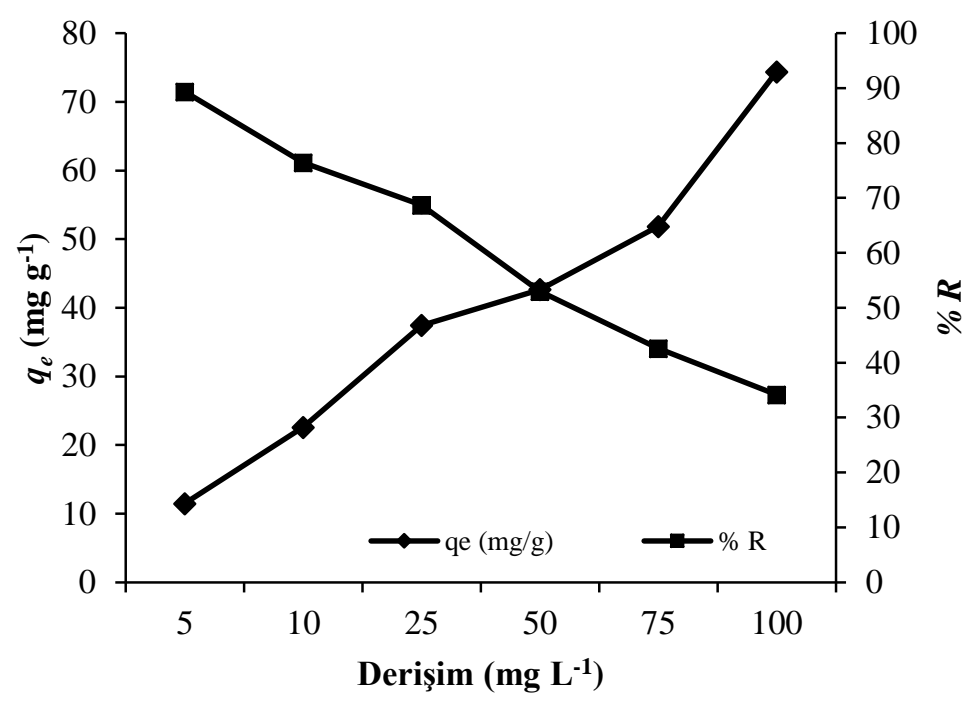

Şekil 5. Başlangıç boyar madde derişiminin $q_{e}$ ve $\% R$ üzerine etkisi

\section{Biyosorpsiyona sıcaklığın etkisi}

Biyosorpsiyon kimyasında bir diğer önemli parametre de sicaklıktır (Mondal vd., 2017). Biyosorpsiyona sicaklığın etkisinin incelenebilmesi için $25 \mathrm{mg} \mathrm{L}^{-1}$ derişiminde toplam hacim $25 \mathrm{~mL}$ olacak şekilde boyar madde örnekleri hazırlanmış ve $277 \mathrm{~K}, 298$ $\mathrm{K}$ ve 318 K'de biyosorpsiyon gerçekleştirilmiştir. Biyosorbent miktarı $0.025 \mathrm{~g}$, biyosorpsiyon süresi 3 saat ve karıştırma hızı 125 rpm olarak ayarlanmıştır. Elde edilen sonuçlara göre, sıcaklık değeri $\operatorname{arttıkça~} q_{e}$ ve $\% R$ değerinde de bir artış gözlenmiştir. Buna göre $277 \mathrm{~K}$ 'de $q_{e}$ değeri $21.18 \mathrm{mg} \mathrm{g}^{-1}$ iken, $318 \mathrm{~K}^{\prime}$ de $47.46 \mathrm{mg} \mathrm{g}^{-1}$ olarak bulunmuştur (Şekil 6a). Aynı şekilde $\% R$ değeri de \% 59.91'den \% 90.05'e artmıştır (Şekil 6b). Sicaklığın artmasıyla $q_{e}$ değerinin artması, biyosorbent üzerindeki fonksiyonel bağlanma bölgelerinin artmas1 ve bu bölgelerin aktif hale gelmesinin bir sonucudur (Yang ve Hong, 2018). Ayrica biyosorpsiyonun ilk 90 dakika hızlı olduğu, daha sonra yavaş ilerleyerek dengeye ulaştığı gözlenmiştir. 


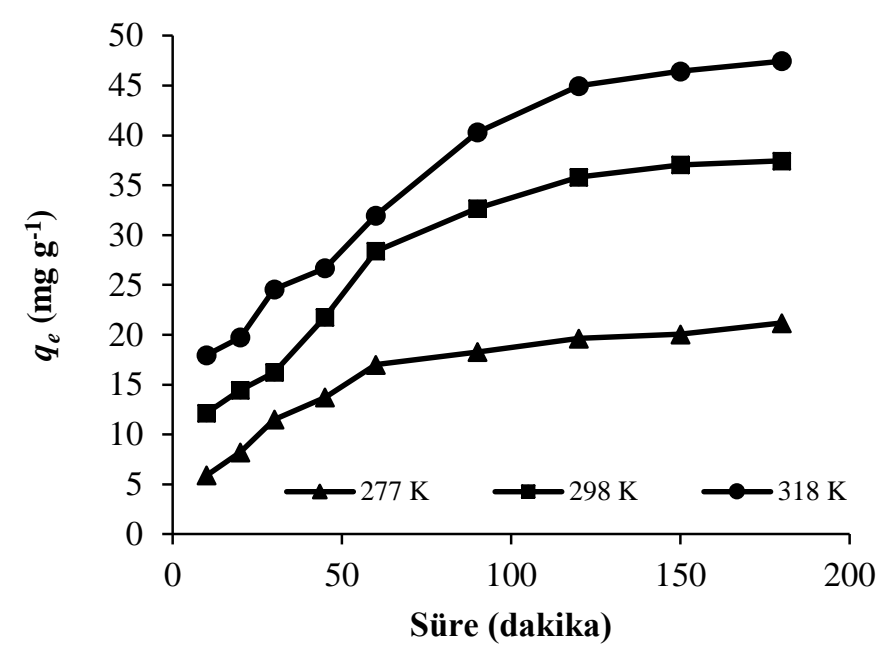

(a)

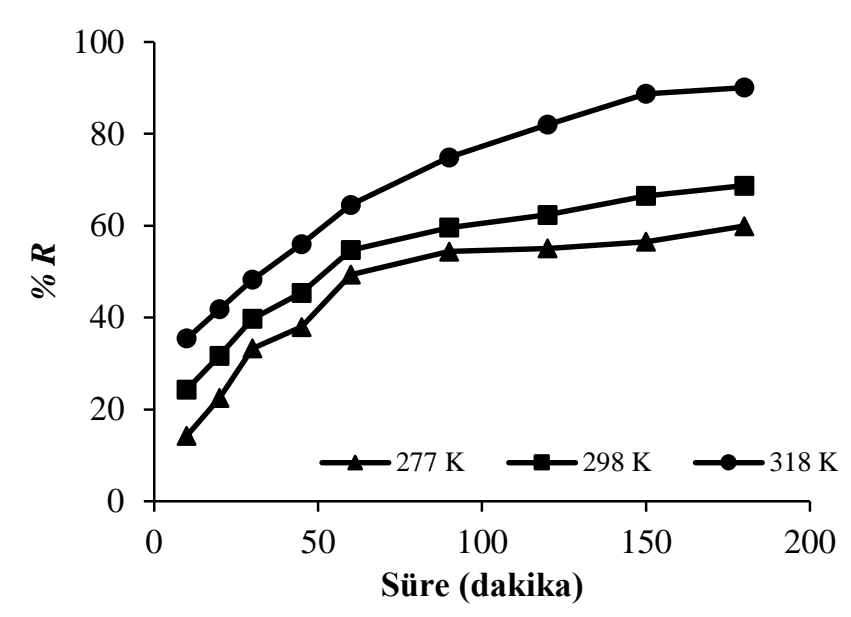

(b)

Şekil 6. Sicaklığın (a) $q_{e}$ ve (b) $\% R$ üzerine etkisi

\section{Biyosorpsiyona biyosorbent miktarının etkisi}

Biyosorbent olarak kullanılan A. campestris biyokütle miktarının biyosorpsiyon üzerine etkisinin incelenmiştir. $\mathrm{Bu}$ amaçla farklı miktarlardaki biyosorbent $(0.010 \mathrm{~g}, 0.025 \mathrm{~g}$ $, 0.050 \mathrm{~g}, 0.1 \mathrm{~g})$ ile sabit derişimdeki DB2 çözeltisi $\left(25 \mathrm{mg} \mathrm{L}^{-1}\right)$ toplam hacim $25 \mathrm{~mL}$ olacak şekilde 3 saat $298 \mathrm{~K}$ 'de (125 rpm) biyosorbe edilmiştir. Elde edilen sonuçlara göre, biyosorbent miktarı arttıkça $\% R$ değeri de artış göstermektedir. Bunun nedeni olarak, ortamdaki biyosorbent miktarının artmasıyla biyosorpsiyonun gerçekleşmesini sağlayan aktif bölgelerin miktarında da artış göstermesidir (Wang vd., 2018). Şekil 7'de gösterildiği gibi 0.010 g biyosorbentin kullanıldığ1 biyosorpsiyon işleminde \% R değeri \% 55.60 iken, bu değer $0.100 \mathrm{~g}$ biyosorbentin kullanılmasiyla \% 93.39'a çıkmıştır. Bunun yanı sıra $q_{e}$ değerlerinde biyosorbent miktarının artmasıyla bir düşüş gözlenmektedir. Bunun nedeni biyosorpsiyon esnasında aktif bölgelerin yeterli doygunluğa ulaşamamasıdır. (Wang vd., 2018). 0.010 g biyosorbentin kullanıldığı biyosorpsiyon işleminde $q_{e}$ değeri $38.56 \mathrm{mg} \mathrm{g}^{-1}$ iken, bu 
değer $0.100 \mathrm{~g}$ biyosorbentin kullanılmasıyla $15.59 \mathrm{mg} \mathrm{g}^{-1}$ ’e düşmüştür (Şekil 7).

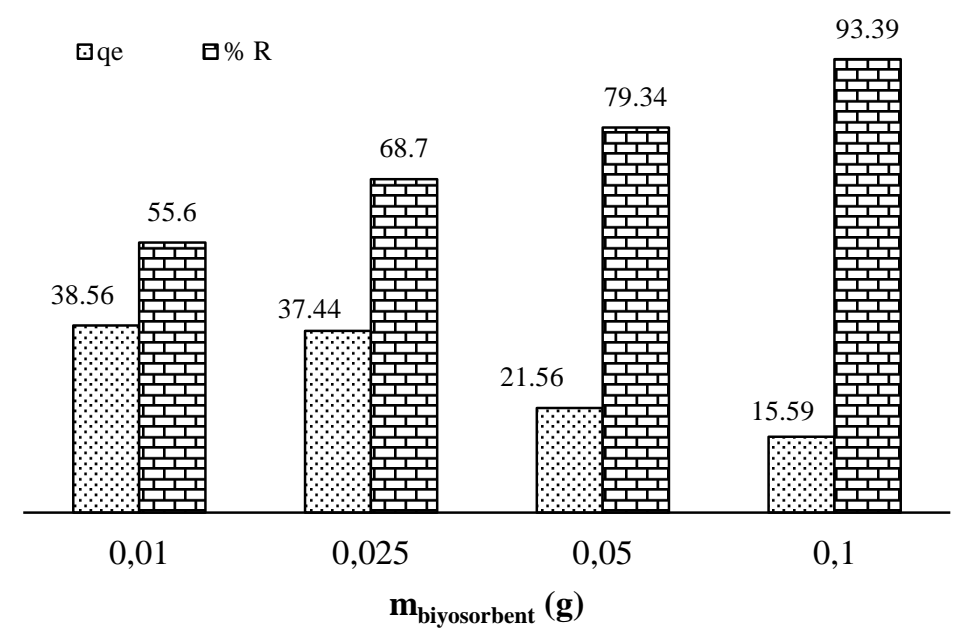

Şekil 7. Biyosorbent miktarının $q_{e}$ ve $\% R$ üzerine etkisi

\section{Desorpsiyon ve tekrar kullanım}

Biyosorpsiyon sonrası biyokütlenin tekrar kullanımının sağlanabilmesi için desorpsiyon işlemi oldukça önemlidir. Fakat kullanılan biyosorpsiyon ajanının biyosorbente zarar vermemesi gerekir (Fomina ve Gadd, 2014). $\mathrm{Bu}$ nedenle DB2'nin A. campestris biyokütlesinden desorpsiyonu için $0.1 \mathrm{~N} \mathrm{HCl}$ ve $0.1 \mathrm{~N} \mathrm{NaOH}$ kullanılmıştır. Elde edilen sonuçlara göre $0.1 \mathrm{~N} \mathrm{HCl}$ için desorpsiyon verimi \%97.35 olarak hesaplanırken, $0.1 \mathrm{~N}$ $\mathrm{NaOH}$ için \% 56.47 olarak hesaplanmıştır. Biyosorbentin tekrar kullanımının araştırılması için 5 tekrarlı biyosorpsiyondesorpsiyon işlemi uygulanmış ve biyosorpsiyon kapasitesinin yalnızca $\% 8$ oranında düştüğü belirlenmiştir. Elde edilen sonuçlara göre A. campestris biyokütlesinin sulu çözeltilerden DB2 biyosorpsiyonu için uygun bir biyosorbent olarak kullanılabileceği ve desorpsiyon sonunda tekrar kullanılabileceği belirlenmiştir.

\section{Biyosorpsiyon izotermleri}

Biyosorbentin yüzeyinde oluşan biyosorpsiyon olayının aydınlatılabilmesi için Langmuir, Freundlich ve Sips
(Langmuir-Freundlich)

izoterm modellerinden yararlanılmıştır. Langmuir izoterm modeli Eşitlik 3'teki gibi ifade edilmektedir (Langmuir, 1918):

$\frac{C_{e}}{q_{e}}=\frac{1}{Q_{L} K_{L}}+\frac{C_{e}}{Q_{L}}$

$C_{e}$ biyosorpsiyon sonrası dengedeki çözeltide bulunan DB2 derişimi (mg L $\left.{ }^{-1}\right), q_{e}$ biyosorbe olan DB2 miktarı $\left(\mathrm{mg} \mathrm{g}^{-1}\right), Q_{L}$ maksimum biyosorpsiyon kapasitesi $\left(\mathrm{mg} \mathrm{g}^{-1}\right), K_{L}$ ise Langmuir sabitini vermektedir. Deneysel sonuçlar ile $C_{e}$ 'ye karşı çizilen $C_{e} / q_{e}$ grafiği çizilmiş, Eşitlik 3 kullanılarak $Q_{L}$ ve $K_{L}$ değerleri hesaplanmıştır (El-Halwany, 2010).

Freundlich izoterm hesabı Eşitlik 4'te verilmiştir (Freundlich, 1906):

$\ln q_{e}=\ln K_{F}+\frac{1}{n} \ln C_{e}$

$q_{e}$ denge anındaki biyosorbent üzerine biyosorbe olan DB2 miktarını (mg g $\left.{ }^{-1}\right), K_{F}$ biyosorpsiyon kapasitesini (mg $\left.\mathrm{g}^{-1}\right), \quad n$ Freundlich izoterm sabitini, $C_{e}$ denge halinde çözelti ortamında kalan DB2 derişimini (mg $\mathrm{L}^{-1}$ ) vermektedir. 
Langmuir ve Freundlich modellerinin bir kombinasyonu olan Sips izoterm modeli (Foo ve Hameed, 2010) aşağıda verilen eşitlik ile hesaplanmıştır (Eşitlik 5):

$\frac{1}{q_{e}}=\frac{1}{Q_{\max } K_{S}}\left(\frac{1}{C_{e}}\right)^{1 / n}+\frac{1}{Q_{\max }}$

$q_{e}$ denge anındaki biyosorbent üzerine biyosorbe olan DB2 miktarın $\left(\mathrm{mg} \mathrm{g}^{-1}\right), K_{S}$ Sips izoterm modeli sabitini $\left(\mathrm{L} \mathrm{mg}^{-1}\right), n$ Sips izoterm sabitini (mg), $Q_{\max }$ maksimum biyosorpsiyon kapasitesini $\left(\mathrm{mg} \mathrm{g}^{-1}\right), C_{e}$ denge halinde çözelti ortamında kalan DB2 derişimini $\left(\mathrm{mg} \mathrm{L}^{-1}\right)$ vermektedir.

A. campestris biyokütlesinin DB2 biyosorpsiyonu için biyosorbent olarak kullanıldığı sistemde her üç sıcaklık değeri (277 K, 298 K, 318 K) için Langmuir, Freundlich ve Sips izoterm modelleri hesaplanarak Tablo 1'de ilgili değerler ve regresyon katsayıları $\left(\mathrm{R}^{2}\right)$ verilmiştir. Langmuir izoterm modeli, sinırlı biyosorpsiyon alanına sahip tek tabakalı izoterm modelidir. Freundlich izoterm modeli ise heterojen yüzeyler için çok tabakalı bir izoterm modelidir. Yüzeyin heterojenitesi, $1 / n$ değerinin sıfıra yakın olmasına bağlıdır (Özüdoğru ve Merdivan, 2017). Elde edilen sonuçlara göre $1 / n$ değeri sirasiyla $0.045, \quad 0.069$ ve 0.076 olarak bulunmuştur. $\mathrm{Bu}$ da yüzeyin oldukça heterojen olduğunun bir göstergesidir. Sips izoterm modeline göre maksimum biyosorpsiyon kapasitesi her üç sıcaklık değeri için sırasıyla $2.71 \mathrm{mg} \mathrm{g}^{-1}, 3.69 \mathrm{mg} \mathrm{g}^{-1}$ ve $4.78 \mathrm{mg} \mathrm{g}^{-1}$ olarak bulunmuştur. $\mathrm{R}^{2}$ değerleri kıyaslandığında en yüksek değer Freundlich izoterm modelinde görülmüştür. Buna göre DB2'nin A. campestris biyokütlesi kullanılarak gerçekleştirilen biyosorpsiyonunda en uygun modelin Freundlich izoterm modeli olduğunu göstermektedir.

Tablo 1. Biyosorbentin DB2 biyosorpsiyonu için izoterm modelleri

\begin{tabular}{lll}
\multicolumn{3}{c}{ Sicaklık (K) } \\
\hline $277 \quad 298 \quad 318$ \\
\hline
\end{tabular}

\begin{tabular}{|c|c|c|c|}
\hline $\begin{array}{l}\text { Langmuir } \\
\text { Modeli }\end{array}$ & & & \\
\hline$K_{L} \times 10^{2}\left(\mathrm{~L} \mathrm{mg}^{-1}\right)$ & 2.52 & 2.74 & 4.18 \\
\hline$Q_{L}\left(\mathrm{mg} \mathrm{g}^{-1}\right)$ & 61.35 & 87.72 & 92.59 \\
\hline$\widetilde{R}^{2}$ & 0.98 & 0.88 & 0.90 \\
\hline $\begin{array}{l}\text { Freundlich } \\
\text { Modeli }\end{array}$ & & & \\
\hline$K_{F}\left(\mathrm{~L} \mathrm{mg}^{-1}\right)$ & 0.12 & 0.24 & 0.25 \\
\hline$n$ & 22.17 & 14.49 & 13.04 \\
\hline $\mathbf{R}^{2}$ & 0.96 & 0.98 & 0.97 \\
\hline Sips İzot & & & \\
\hline$K_{S} \times 10^{2}(\mathrm{~L}$ & 67.71 & 70.44 & 78.09 \\
\hline$Q_{\max }(\mathrm{mg}$ & 2.71 & 3.69 & 4.78 \\
\hline $\mathbf{R}^{2}$ & 0.96 & 0.86 & 0.94 \\
\hline
\end{tabular}

Çeşitli tekstil boyar maddelerin biyosorpsiyonunda kullanılan farklı mantar türlerine ait biyokütlelere ait izoterm modelleri Tablo 2'de verilmiştir. 
Direct Blue 2 Tekstil Boyar Maddesinin Agaricus campestris Biyokütlesi Tarafından Biyosorpsiyonu: Kinetik, İzotermal ve Termodinamik Çalışmalar

Tablo 2. Farklı biyosorbentler için izoterm modelleri

\begin{tabular}{|c|c|c|c|c|c|c|}
\hline Biyosorbent & Boya & \multicolumn{2}{|c|}{$\begin{array}{l}\text { Biyosorpsiyon } \\
\text { kapasitesi }\left(\mathrm{mg} \mathrm{g}^{-1}\right)\end{array}$} & $\begin{array}{l}\% \text { Tutunma } \\
\text { değeri }(\% R)\end{array}$ & $\begin{array}{l}\text { İzoterm } \\
\text { modeli }\end{array}$ & Kaynak \\
\hline Coriolus versicolor & $\begin{array}{l}\text { Malachite } \\
\text { Green }\end{array}$ & \multicolumn{2}{|l|}{-} & 70.29 & - & $\begin{array}{c}\text { Cikcikoglu } \\
\text { Y1ldırım } \\
\text { vd., } 2018\end{array}$ \\
\hline Ganoderma sp. & $\begin{array}{l}\text { Reactive } \\
\text { Red } 120\end{array}$ & \multicolumn{2}{|l|}{44.44} & - & Langmuir & $\begin{array}{l}\text { Souza vd., } \\
2017\end{array}$ \\
\hline $\begin{array}{l}\text { Aspergillus } \\
\text { brasiliensis }\end{array}$ & $\begin{array}{l}\text { Reactive } \\
\text { Blue } 19\end{array}$ & \multicolumn{2}{|l|}{-} & 78.67 & $\begin{array}{l}\text { Langmuir } \\
\text { ve } \\
\text { Freundlich }\end{array}$ & $\begin{array}{l}\text { Pohontu, } \\
2019\end{array}$ \\
\hline $\begin{array}{l}\text { Beyaz çürükçül } \\
\text { mantar atıkları }\end{array}$ & $\begin{array}{l}\text { Methyelen } \\
\text { Blue }\end{array}$ & 23.69 & & - & Langmuir & $\begin{array}{l}\text { Abbas vd., } \\
2018\end{array}$ \\
\hline $\begin{array}{l}\text { Ferromanyetik } \\
\text { nanopartikül } \\
\text { destekli Yarrowia } \\
\text { lipolytica }\end{array}$ & $\begin{array}{l}\text { Tartrazin } \\
\text { Ponceau 4R }\end{array}$ & $\begin{array}{l}90.83 \\
101.46\end{array}$ & & - & Langmuir & $\begin{array}{l}\text { Asfaram } \\
\text { vd., } 2018\end{array}$ \\
\hline $\begin{array}{l}\text { Bjerkandera } \\
\text { agustavia }\end{array}$ & $\begin{array}{l}\text { Sentetik } \\
\text { tekstil } \\
\text { atıksuyu }\end{array}$ & - & & 53.55 & - & $\begin{array}{l}\text { Astuti ve } \\
\text { Muda, } \\
2018\end{array}$ \\
\hline $\begin{array}{l}\text { Trichoderma } \\
\text { harzianum }\end{array}$ & $\begin{array}{l}\text { Reactive } \\
\text { Black B }\end{array}$ & - & & 97.47 & Freundlich & $\begin{array}{l}\text { Karthik vd., } \\
\quad 2019\end{array}$ \\
\hline $\begin{array}{l}\text { Agaricus } \\
\text { campestris }\end{array}$ & $\begin{array}{l}\text { Direct Blue } \\
2\end{array}$ & 38.56 & & 93.39 & Freundlich & $\begin{array}{l}\text { Mevcut } \\
\text { çalışma }\end{array}$ \\
\hline $\begin{array}{l}\text { Biyosorpsiyon } \\
\text { aydınlatılabilmesi i } \\
\text { biyosorpsiyon kin } \\
\text { 2007). Bu nedenl } \\
\text { yalancı-ikinci dere } \\
\text { modellerinden } \\
\text { biyosorpsiyonun } \\
\text { çalış1lmıştır. Ya } \\
\text { kinetik model Lage } \\
\text { hı denkleminden } \\
\text { ve Svenska, 1898) }\end{array}$ & $\begin{array}{l}\text { me } \\
\text { çin bir diğer } \\
\text { etikleridir ( } \\
\text { e, yalanc1-bi } \\
\text { ce ve partikü } \\
\text { kinetiği a) } \\
\text { lanc1-birinci } \\
\text { rgren'in biri } \\
\text { belirlenebili } \\
\text { (Eşitlik 6): }\end{array}$ & $\begin{array}{l}\text { kanizmasının } \\
\text { önemli faktör } \\
\text { Hameed vd., } \\
\text { rinci derece, } \\
\text { l içi difüzyon } \\
\text { yararlanılarak } \\
\text { ydınlatılmaya } \\
\text { dereceden } \\
\text { ci dereceden } \\
\text { r (Lagergren }\end{array}$ & \multicolumn{4}{|c|}{$\begin{array}{l}q_{e} \text { denge durumunda biyosorbent tarafından } \\
\text { biyosorbe edilen DB2 miktarını }\left(\mathrm{mg} \mathrm{g}^{-1}\right), q_{t} \\
\text { herhangi bir } t \text { anında biyosorbent tarafından } \\
\text { biyosorbe edilen DB2 miktarını }\left(\mathrm{mg} \mathrm{g}^{-1}\right), k_{l} \\
\text { ise denge hız sabitini }\left(1 \mathrm{dk}^{-1}\right) \text { vermektedir. ln } \\
\left(q_{e}-q_{t}\right) \text { 'ye karşı } t \text { grafiği çizildiğinde elde } \\
\text { edilen doğrunun eğiminden } k_{1} \text { değeri, kesim } \\
\text { noktasından ise } q_{e} \text { değeri hesaplanır. } \\
\text { Bazı durumlarda yalancı-birinci dereceden } \\
\text { kinetik model, tüm biyosorpsiyon süresinin } \\
\text { kinetiğinin belirlenmesinde yetersiz kalır. Bu } \\
\text { durumda, yalanc1-ikinci dereceden kinetik } \\
\text { model türetilmiştir (Özacar ve Şengil, 2003) } \\
\text { (Eşitlik 7): }\end{array}$} \\
\hline
\end{tabular}


$\frac{t}{q_{t}}=\frac{1}{k_{2} q_{e}^{2}}+\frac{t}{q_{e}}$

$k_{2}\left(\mathrm{~g} \mathrm{mg}^{-1} \mathrm{dk}^{-1}\right)$ yalanc1-ikinci dereceden h1z sabitini vermektedir. $k_{2}$ ve $q_{e}$ değerleri, $t / q_{t}$ 'ye karşı çizilen $t$ grafiğinin eğim ve kesim noktasindan bulunur (Ho ve McKay, 1998; Chen ve Bai, 2013).

Partikül içi difüzyon modeli Weber Morris eşitliği ile ifade edilmektedir (Eşitlik 8):

$q_{t}=k_{i d} t^{1 / 2}$

Buradaki $q_{t} t$ anındaki biyosorpsiyon kapasitesini (dk), $t^{1 / 2}$ saniyedeki yarılanma zamanını, $k_{i d}$ farklı DB2 derişimlerindeki partikül içi difüzyon hız sabitini $\left(\mathrm{mg} \mathrm{g}^{-1} \mathrm{dk}^{-}\right.$ $\left.{ }^{(1 / 2)}\right)$ vermektedir. $q_{t}$ ve $t^{1 / 2}$ arasındaki doğrusal ilişki partikül içi difüzyonun biyosorpsiyonda etkili olduğunu ve partikül içi difüzyonun hız belirleyen basamak olduğunu göstermektedir (Mahmoud ve ark., 2016).

Elde edilen verilere göre biyosorbent olarak kullanılan A. campestris biyokütlesine DB2 biyosorpsiyonunun mekanizmasının aydınlatılabilmesi için üç farklı kinetik modelden yararlanılmış ve biyosorpsiyonun yalanc1-ikinci derece kinetik modele uyduğu gözlenmiştir Tablo 2). Deneysel ve hesapsal $q_{e}$ değerleri karşılaştırıldığında yine yalancıikinci derece kinetik modelde hesaplanan değerlerin deneysel değerlere yakın olduğu tespit edilmiştir. Bunun yanı sıra korelasyon $\left(\mathrm{R}^{2}\right)$ değerleri de diğer kinetik modellere kiyasla yalanc1-ikinci derece kinetik modelde daha yüksek çıkmıştır (Tablo 3).
Tablo 3. Biyosorbentin DB2 biyosorpsiyonu için kinetik modeller

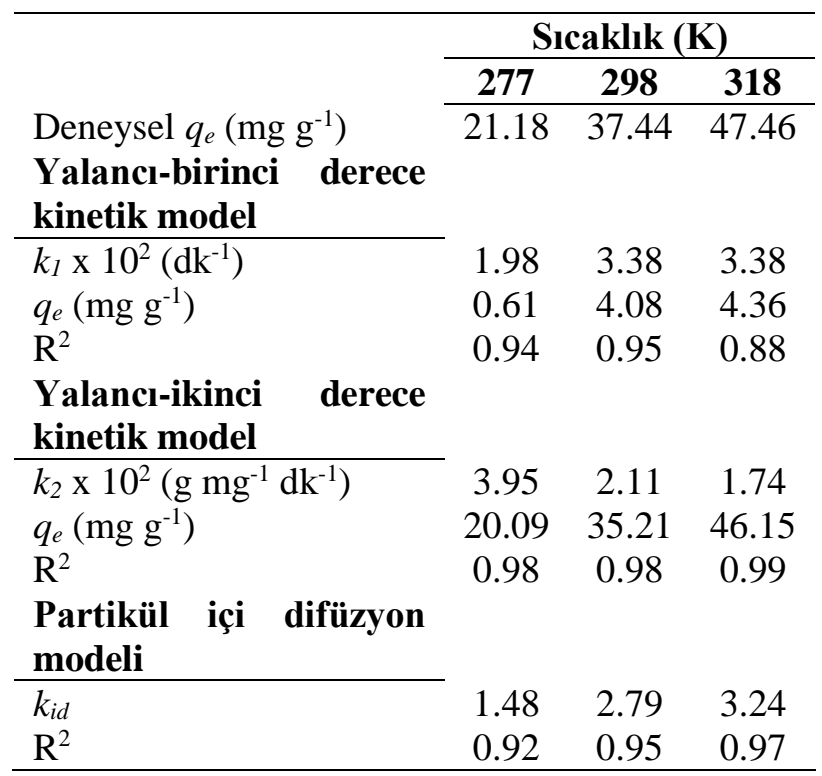

\section{Biyosorpsiyonun termodinamiği}

Serbest enerji değişimi $\left(\Delta G^{o}\right)$, entalpi değişimi $\left(\Delta H^{\sigma}\right)$ ve entropi değişimi $\left(\Delta S^{\sigma}\right)$ gibi termodinamik parametreler her üç sicaklık değeri için van't Hoff eşitliğinden yararlanılarak hesaplanmıştır (Eşitlik 9).

$\ln K_{L}=-\frac{\Delta H^{\circ}}{R T}+\frac{\Delta S^{\circ}}{R}$

$K_{L}$ Langmuir sabitini, $T$ mutlak sıcaklığı $(\mathrm{K})$, $R$ ise evrensel gaz sabitini $\left(8.314 \mathrm{~J} \mathrm{~mol}^{-1} \mathrm{~K}^{-1}\right)$ vermektedir. $\Delta H^{o}$ ve $\Delta S^{o}$, ln $K_{L}^{\prime}$ ye karş1 çizilen $1 / T$ grafiğinden elde edilen doğrunun eğiminden ve kesim noktasından bulunabilir (Göçenoğlu Sarıkaya, 2019b). Elde edilen veriler Tablo 4'de verilmiştir. $\Delta H^{o}$ değerinin negatif olmas1, DB2 biyosorpsiyonunun ekzotermik karakterde olduğunu gösterir. Bunun yanı sıra, $\Delta G^{o}$ değerinin her üç sıcaklık değeri için negatif çıkması biyosorpsiyonun kendiliğinden gerçekleştiğinin bir ispatıdır. 
Tablo 4. Biyosorbentin DB2 biyosorpsiyonu için termodinamik parametreler

\begin{tabular}{cccc}
\hline $\mathbf{T}(\mathbf{K})$ & $\begin{array}{l}\Delta \mathbf{H}^{\mathbf{0}} \\
\left(\mathbf{k J ~ m o l} \mathbf{~ m o l}^{-1}\right)\end{array}$ & $\begin{array}{l}\Delta \mathbf{S}^{\mathbf{o}} \\
\left(\mathbf{J ~ m o l}^{\mathbf{- 1}} \mathbf{K}^{-\mathbf{1}}\right)\end{array}$ & $\begin{array}{l}\Delta \mathbf{G}^{\mathbf{0}} \\
\left(\mathbf{k J ~} \mathbf{~ m o l}^{-\mathbf{1}}\right)\end{array}$ \\
\hline 277 & & & -1.83 \\
298 & -9.96 & -31.51 & -1.69 \\
318 & & & -1.53 \\
\hline
\end{tabular}

\section{Sonuç}

Bu çalışmada, A. campestris biyokütlesinin DB2 tekstil boyar maddesinin biyosorpsiyonunda biyosorbent olarak kullanılabilirliği araştırılmıştır. Bu amaçla ilk önce biyosorbent uygun şartlarda hazırlanarak FT-IR ve SEM analizleri gerçekleştirilmiştir. Daha sonra uygun biyosorpsiyon koşullarının belirlenebilmesi için biyosorpsiyona $\mathrm{pH}$, boyar madde derişimi, süre ve sıcaklık etkisi incelenmiştir. Biyosorbent miktarının biyosorpsiyon üzerine etkisi ve biyosorbentin desorpsiyonu ve tekrar kullanımı belirlenmiştir. Elde edilen verilerden yola çıkarak biyosorpsiyonun doğası aydınlatılmıştır. Bunun için uygun izoterm modelleri, termodinamik parametreler ve kinetik modeller hesaplanmıştır. Sonuç olarak, biyosorpsiyonun ilk 90 dakikada hızlı bir şekilde gerçekleştiği, 120 dakikada dengeye geldiği belirlenmiştir. Boyar madde derişiminin artmasıyla biyosorpsiyon kapasitesinde $\left(q_{e}\right)$ artış gözlenirken \% tutunma değerinde $(\% R)$ azalma gözlenmektedir. Sicaklığın artmasıyla $q_{e}$ ve $\% \quad R$ değerleri artmıştır. Biyosorpsiyon mekanizmas1 aydınlatılarak biyosorpsiyonun Freundlich izoterm modeline ve yalanc1ikinci derece kinetik modele uygun olduğu tespit edilmiştir. Standart serbest enerji, standart entalpi $\left(\Delta H^{0}=-9.96 \mathrm{~kJ} \mathrm{~mol}^{-1}\right)$ ve standart entropi $\left(\Delta S^{0}=-31.51 \mathrm{~J} \mathrm{~mol}^{-1} \mathrm{~K}^{-1}\right)$ değerleri hesaplanmıştır. Sonuç olarak bu çalışma, yenilebilen bir mantar türü olan $A$. campestris'in yaygın olarak kullanılan tekstil boyar maddesi olan DB2'nin sulu çözeltilerden biyosorpsiyonunda etkili bir biyosorbent olarak kullanılabilirliği, biyosorplama kapasitesinde çok fazla bir değişim olmadan tekrar kullanılabileceğini göstermektedir.

Teşekkür: $\mathrm{Bu}$ çalışmanın gerçekleşmesi esnasında yardımlarını esirgemeyen Prof. Dr. Nurdan Kaşıkara Pazarlığlu'na teşekkür ederiz.

\section{Kaynaklar}

Abbas S. H., Ahmed M. A. A-K. ve Ali W. H. 2018. 'Biosorption of Methyelen Blue from aqueous solution using wastes micelium of fungal biomass type White rot fungi', Journal of Engineering and Sustainable Development, 22(4), 229-246.

Almeida, E. J. R. ve Corso, C. R. 2019. 'Decolorization and Removal of Toxicity of Textile Azo Dyes Using Fungal Biomass Pelletized', International Journal of Environmental Science and Technology, 16(3), 1319-1328.

Asfaram, A., Ghaedi, M., Dashtian, K. ve Ghezelbash, G. R. 2018. 'Preparation and Characterization of $\quad \mathrm{Mn}_{0.4} \mathrm{Zn}_{0.6} \mathrm{Fe}_{2} \mathrm{O}_{4}$ Nanoparticles Supported on Dead Cells of Yarrowia lipolytica as a Novel and Efficient Adsorbent/Biosorbent Composite for the Removal of Azo Food Dyes: Central Composite Design Optimization Study', ACS Sustainable Chemical Engineering, 6(4), 4549-4563.

Astuti A. D. ve Muda K. 2018. '’Biosorption process of synthetic textile waste-water using Bjerkandera agustavia response surface methodology (RSM)", E3S Web of Conferences, 68, 04020.

Bayazıt, G., Gül, Ü. D. ve Ünal, D. 2018. 'Biosorption of Acid Red P-2BX by Lichens as Low-Cost Biosorbents', International Journal of Environmental Studies, Doi: 10.1080/00207233.2018.1502959

Bayramoğlu, G. ve Arıca, M. Y. 2007. 'Biosorption of Benzidine Based Textile Dyes 'Direct Blue 1 and Direct Red 128", Using Native and Heat-treated Biomass of Trametes versicolor', Journal of Hazardous Materials, 143(1-2), 135-143. 
Cardoso, N. F., Lima, E. C., Royer, B., Bach, M. V., Dotto, G. L., Pinto, L. A. A. ve Calvete, T. 2012. 'Comparison of Spirulina platensis Microalgae and Commercial Activated Carbon as Adsorbents for the Removal of Reactive Red 120 Dye from Aqueous Effluents', Journal of Hazardous Materials, 241-242, 146-153.

Chen, L. ve Bai, B. 2013. 'Equilibrium, Kinetic, Thermodynamic, and in situ Regeneration Studies about Methylene Blue Adsorption by the Rasberry-like TiO2@yeast Microspheres. Industrial \& Engineering Chemistry Research, 52, 15568-15577.

Chu, W.-L. ve Phang, S.-M. 2019. 'Biosorption of Heavy Metals and Dyes from Industrial Effluents by Microalgae', In: Alam, M., Wang, Z. (eds), Microalgae Biotechnology for Development of Biofuel and Wastewater Treatment, 599-634, Springer, Singapore.

dos Santos, B. A. P., Cossolin, A. S., dos Reis, H. C. O., de Castro, K. C., da Silva, E. R., de Menezes Pereira, G., de Sousa Junior, P. T., Dall'Oglio, E. L., de Vasconcelos, L. G. ve de Morais, E. B. 2019. ' 'Baker's yeast$\mathrm{MnO} 2$ Composites as Biosorbent for Malachite Green: An Ecofriendly Approach for Dye Removal From Aqueous Solution', Ambiente \& Agua - An Interdisciplinary Journal of Applied Science, 14(1), 1-15.

El-Halwany, M. M. 2010. 'Study of Adsorption Isotherms and Kinetic Models for Methylene Blue Adsorption on Activated Carbon Developed from Egyptian Rice Hull (Part II)', Desalination, 250, 208-213.

Fernandez, P. M., Farina, J. I. ve Figueroa, L. I. C. 2010. "The Significance of Inoculum Standardization and Cell Density on the $\mathrm{Cr}(\mathrm{VI})$ Bioremediation by Environmental Yeast Isolates", Water, Air, Soil Pollution, 212, 275-279.

Fomina, M. ve Gadd, G. M. 2014. 'Biosorption: Current Perspectives on Concept, Definition and Application', Bioresource Technology, 160, 3-14.
Foo, K. Y. ve Hameed, B. H. 2010. ' Insights into the Modeling of Adsorption Isotherm Systems", Chemical Engineering Journal, 156(1), 2-10.

Freundlich, H. 1906. "Over the Adsorption in Solution', The Journal of Physical Chemistry, 57, 385.

Göçenoğlu Sarıkaya, A. 2019a. ' Direct Blue 2 diazo-boyarmaddesinin sulu çözeltiden P(HEMA) nanopartiküller ile uzaklaştırılması', Balıkesir Üniversitesi Fen Bilimleri Enstitüsü Dergisi, 21(1), 278-294.

Göçenoğlu Sarıkaya, A. 2019b. " Kinetic and thermodynamic studies of the biosorption of $\mathrm{Cr}$ (VI) in aqueous solutions by Agaricus campestris', Environmental Technology,

10.1080/09593330.2019.1620867.

Güzel, F., Sayğılı, H., Sayğılı, G. A. ve Koyuncu, F. 2014. 'Decolorisation of Aqueous Crystal Violet Solution by a New Nanoporous Carbon: Equilibrium and Kinetic Approach', Journal of Indian Engineering Chemistry, 20(5), 3375-3386.

Hameed, B. H., Ahmad, A. L. ve Latiff, K. N. A. 2007. "Adsorption of Basic Dye (Methylene Blue) onto Activated Carbon Prepared from Rattan Sawdust', Dyes and Pigments, 75, 143-149.

Ho, Y. S. ve McKay, G. 1998. 'Sorption of Dye from Aqueous Solution by Peat', Chemical Engineering Journal, 70, 115-124.

Jain, S. N. ve Gogate, P. R. 2019. ' Efficient Removal of Acid Green 25 Dye from Wastewater Using Activated Prunus Dulcis as Biosorbent: Batch and Column Studies", Journal of Environmental Management, 210, 226-238.

Karthik V., Sivarajasekar N., Padmanaban V. C., Nakkeeran E. ve Selvaraju N. 2019. 'Biosorption of xenobiotic Reactive Black B onto metabolically inactive $T$. harzianum biomass: optimization and equilibrium studies", International Journal of Environmental Science and Technology, 16, 3625-3636. 
Lagergren, S. ve Svenska, B. K. 1898. 'Zur Theorie der Sopenannten Adsorption Geloester Stoffe', Vaternskapsakad Handlingar, 24(4), 1-39.

Langmuir, I. 1918. "The Adsorption of Gases on Plane Surfaces of Glass, Mica and Platinum', Journal of American Chemical Society, 40, 1361-1403.

Li, H.-h., Wang, Y.-t., Wang, Y., Wang, H.X., Sun, K.-k. ve Lu, Z.-m. 2019. ''Bacterial Degradation of Anthraquinone Dyes", Journal of Zhejiang University-SCIENCE B, 20(6), 528-540.

Mahmoud, M. E., Nabil, G. M., El-Mallah, N. M., Bassiouny, H. I., Kumar, S. ve AbdelFattah, T. M. 2016. ' Kinetics, Isotherm, and Thermodynamic Studies of the Adsorption of Reactive Red 195 a Dye from Water by Modified Switchgrass Biochar Adsorbent', Journal of Industrial and Engineering Chemistry, 37: 156-167.

Mondal, N. K., Samanta, A., Dutta, S. ve Chattoraj, S. 2017. ' Optimization of Cr(VI) Biosorption onto Aspergillus niger Using 3level Box-Behnken Design: Equilibrium, Kinetic, Thermodynamic and Regeneration Studies', Journal of Genetic Engineering and Biotechnology, 15, 151-160.

Özacar, M. ve Şengil, I. A. 2003. 'Adsorption of Reactive Dyes on Calcined Alunite from Aqueous Solutions", Journal of Hazardous Materials, 98(1-3), 211-224.

Özüdogru, Y. ve Merdivan, M. 2017. 'Metilen Mavisinin Modifiye Edilmis Cystoseira barbata (stackhouse) c. agardh Kullanilarak Biyosorpsiyonu', Trakya University Journal of Natural Sciences, 18(2), 81-87.

P.S.C. Souza, P. S. C., Santos, J., Souza, A. R., Spessato, L., Pezoti, O., Alves, H. J., Colauto, N. B., Almeida, V. C. ve Dragunskie, D. C. 2018. 'Biosorption of reactive red-120 dye onto fungal biomass of wild Ganoderma stipitatum', Desalination and Water Treatment, 102, 280-288.

Pohontu C. M. 2019. 'Biodecolorization of Reactive Blue 19 dye from effluents by sorption on Aspergillus brasiliensis fungal biomass", Scientific Annals of the Danube Delta Institute, 24, 167-174.

Prola, L. D. T., Machado, F. M., Bergmann, C. P., de Souza F. E., Gally, C. R., Lima, E. C., Adebayo, M. A., Dias, S. L.P. ve Calvete, T. 2013.' Adsorption of Direct Blue 53 Dye from Aqueous Solutions by Multi-walled Carbon Nanotubes and Activated Carbon', Journal of Environmental Management, 130, 166-175.

Rangabhashiyam, S., Lata, S. ve Balasubramanian, P. 2018. "Biosorption Characteristics of Methylene Blue and Malachite Green from Simulated Wastewater onto Carica papaya Wood Biosorbent", Surfaces and Interfaces, 10, 197-215.

Sellaoui, L., Lima, E. C., Dotto, G. L., Dias, S. L. P. ve Lamine, A. B. 2017. 'Physicochemical Modeling of Reactive Violet 5 Dye Adsorption on Home-Made Cocoa Shell and Commercial Activated Carbons Using the Statistical Physics Theory', Results in Physics, 7, 233-237.

Seow, T. W. ve Lim, C. K. 2016. ''Removal of Dye by Adsorption: A Review', International Journal of Applied Engineering Research, 11(4), 2675-2679.

Sewu, D. D., Boakye, P. ve Woo, S. H. 2017. "Highly Efficient Adsorption of Cationic Dye by Biochar Produced with Korean Cabbage Waste", Bioresource Technology, 224, 206-213.

Wang, X. S., Liu, X., Wen, L., Zhou, Y., Jiang, Y. ve Li, Z. 2018. "Comparison of Basic Dye Crystal Violet Removalfrom Aqueous Solution by Low-Cost Biosorbents", Separation Science and Technology, 43, 3712-3731.

Yang, J.X. ve Hong, G.B. 2018. 'Adsorption Behavior of Modified Glossogyne tenuifolia Leaves as a Potential Biosorbent for the Removal of Dyes", Journal of Molecular Liquids, 252, 289- 295.

Yildirim, N. C., Tanyol, M., Yildirim, N., Serdar, O., ve Tatar, S. 2018. 'Biochemical responses of Gammarus pulex to malachite 
Direct Blue 2 Tekstil Boyar Maddesinin Agaricus campestris Biyokütlesi Tarafından Biyosorpsiyonu: Kinetik, İzotermal ve Termodinamik Çalışmalar

green solutions decolorized by Coriolus versicolor as a biosorbent under batch adsorption conditions optimized with response surface methodology', Ecotoxicology and Environmental Safety, 156, 41-47. 